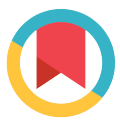

Check for updates

\title{
Comparison of Serum Levels of Vitamin D in Patients With and Without Acute Coronary Syndrome
}

\author{
Reza Hassanzadeh Makoui ${ }^{1}$, Mahsa Soltannejad Dizaji ${ }^{2}$, Hamid \\ Khederlou ${ }^{3, *}$ \\ ${ }^{1}$ Department of Cardiology, Mousavi Hospital, Zanjan University of Medical \\ Sciences, Zanjan, Iran \\ ${ }^{2}$ Mousavi Hospital, Zanjan University of Medical Sciences, Zanjan, Iran \\ ${ }^{3}$ Student Research Center, Zanjan University of Medical Sciences, Zanjan, Iran \\ * Corresponding author: Hamid Khederlou, Student Research Center, Zanjan Uni- \\ versity of Medical Sciences, Zanjan,Iran.E-mail:ham_khed@yahoo.com
}

DOI: $10.21859 / \mathrm{ijcp}-03201$

Submited: $12-27-2017$

Accepted: 10-06-2018

Keywords:

Acute Coronary Syndrome

Vitamin D

Arrhythmias, Cardiac

(c) 2018. International Journal of Cardiovascular Practice.

\begin{abstract}
Introduction: Coronary artery disease is one of the most common causes of mortality around the world. The association between vitamin D deficiency and the incidence of diseases, such as hypertension, diabetes, and metabolic syndrome, has been demonstrated previously. There have been studies concerning the relationship between vitamin $\mathrm{D}$ deficiency and cardiovascular diseases, which have shown different results. Therefore, this study aimed at determining the association between serum levels of vitamin $\mathrm{D}$ and acute coronary syndrome.
\end{abstract}

Methods: In this case-control study, serum levels of vitamin D were compared between 50 patients with acute coronary syndrome and 50 individuals without this syndrome. A checklist, including demographic data of patients, comorbidities, vitamin D levels, lipid profiles, Electrocardiogram (ECG) changes and echocardiography results, was completed during hospitalization.

Results: Mean age in the case and control group was $63.26 \pm 10.76$ and $61.22 \pm 10.71$ years, respectively. The prevalence of diabetes and high blood pressure in the case group was $32 \%$ and $54 \%$ versus $10 \%$ and $8 \%$ in the control group, respectively. Overall, $70 \%$ and $18 \%$ of subjects were smokers in the control and case groups, respectively. Mean concentration of vitamin D in serum was $20.63 \pm 13.90 \mathrm{ng} / \mathrm{mL}$, which was significantly lower than the control group with a mean concentration of $29.54 \pm 16.8 \mathrm{ng} / \mathrm{mL}$ (P-Value $=0.002)$. Finally, it was shown that for every one unit increase in vitamin $\mathrm{D}$ levels, the risk of acute coronary syndrome was reduced by $7 \%(\mathrm{P}$-Value $=0.005)$.

Conclusions: The results of this study showed that the serum levels of vitamin $\mathrm{D}$ were significantly lower in patients with acute coronary syndrome compared to those without this disease.

\section{INTRODUCTION}

Patients with cardiovascular disease, especially coronary artery disease (as the leading factor of high healthcare costs), comprise a significant number of patients admitted to hospitals $[1,2]$. Acute Coronary Syndrome (ACS) is a subgroup of coronary heart diseases, including ST-segment elevation myocardial infarction, non-ST-segment elevation myocardial infarction, and unstable angina [3, 4]. In addition to its high costs of hospitalization and treatment, ACS was considered as one of the most important causes of mortality and morbidity in the recent years [5-7]. Similar to smoking, high cholesterol and Low Density Lipoprotein (LDL), low High Density Lipoprotein (HDL), hypertension, diabetes and stress, and vitamin D Deficiency are among risk factors of cardiovascu- lar diseases [6]. Vitamin D is synthesized in the skin from 7-dehydrocholestrol through the activity of UV radiation, and is converted to its active form of 1,25-dihydroxy vitamin $\mathrm{D}$ in the kidneys $[8,9]$. Recent studies have shown that vitamin D has receptors on vascular endothelium, smooth and cardiac muscles, as well as a role in bone mineralization and calcium transport in the intestine [10]. Vitamin D acts as a protective factor against cardiac hypertrophy and myocardial dysfunction, and its deficiency has been demonstrated in diseases, such as high blood pressure, diabetes, and metabolic syndrome $[11,12]$. The aim of this study was to investigate the relationship between serum levels of vitamin $\mathrm{D}$ and acute coronary syndrome and its short-term effects, including car- 
diac arrhythmia and reduced left ventricular function. Administration of vitamin $\mathrm{D}$ products could be considered to prevent coronary heart disease in case of a significant correlation between vitamin $\mathrm{D}$ levels and ACS.

\section{METHODS}

In this study of case-control, conducted during years 2016 to 2017,50 patients with an age range of 40 to 80 years old admitted to the Coronary Care Unit (CCU), who were diagnosed with ACS (case group) and 50 non-cardiac patients, aged 40 to 80 years old from other wards of Mousavi Hospital of Zanjan (as the control group) were enrolled. After obtaining a license from the Ethics Committee of Zanjan University of Medical Sciences with the following code ZUMS. REC.1393.108, a checklist involving demographic data of patients, including hypertension data, diabetes mellitus, hyperparathyroidism, smoking, consumption of vitamin $\mathrm{D}$ and calcium supplements in the past 3 months, ECG changes and echocardiography, were prepared and completed for patients during hospitalization. The patients consuming vitamin $\mathrm{D}$ or calcium-containing compounds with a history of parathyroid disease were excluded. After providing the necessary explanations and obtaining written informed consent, $1 \mathrm{~mL}$ of fasting venous blood sample was drawn from patients to measure serum Vitamin D levels and lipid profile. Patients hospitalized for acute coronary syndrome was monitored for ECG changes, echocardiographic findings, and cardiac biomarkers during hospitalization.

\section{Statistical Analysis}

Continuous data are expressed as mean $\pm \mathrm{SD}$, and categorical variables as percentages. Simple random sampling was done by calculating the same sample size for both male and female groups. Continuous variables were compared by Student's t-test and categorical variables were compared using the chisquare test. The 2 groups were matched for age and gender. The effect of other confounding variables, including diabetes mellitus, hypertension, dyslipidemia, and smoking was eventually eliminated by logistic regression. Finally, the data were analyzed by the SPSS 20 software. All the statistical tests were calculated and assessed with a significance level of 0.05 .

\section{RESULTS}

This study was conducted on 100 patients admitted to Mousavi Hospital of Zanjan, including 50 patients with ACS and 50 controls. The number of females and males in both groups was the same, with a mean age of $63.26 \pm 10.76$ and $61.22 \pm 10.71$ years in the case and control groups, respectively. Mean level of vitamin D in the case and control groups was $20.63 \pm 13.90$ and $29.54 \pm 16.80 \mathrm{ng} / \mathrm{mL}$ respectively, and mean difference in vitamin $\mathrm{D}$ levels was significant between the 2 groups $(\mathrm{P}=0.002)$. A vitamin $\mathrm{D}$ level of less than $20 \mathrm{ng} / \mathrm{mL}$ was considered as Vitamin D deficiency [13-15]. Overall, $64 \%$ of cases and $34 \%$ of controls had vitamin $\mathrm{D}$ deficiency $(\mathrm{P}=0.011)$, which reflects the significance of vitamin $\mathrm{D}$ deficiency in both groups. Mean level of triglyceride, cholesterol, HDL, and LDL in cases were $166.52 \pm 121.60,195.19 \pm 41.07,41.06 \pm 9.43$, and $109.13 \pm 28.42$ versus $103.44 \pm 59.20,164.60 \pm 38.26$, $43.66 \pm 10.60$, and $92.02 \pm 29.67 \mathrm{mg} / \mathrm{dL}$ in controls, respectively. Mean triglyceride and cholesterol levels were significantly higher in patients with ACS. Also, hypertension, diabetes, and smoking were significantly higher in the case group. Logistic regression model analysis was used to evaluate the impact of each effective factor on ACS with the elimination of other confounding factors. Based on the results, ACS risk was reduced by $7 \%$ per unit increase in vitamin $\mathrm{D}$ levels $(\mathrm{P}=0.005)$. Moreover, hypertension caused a 6.9-fold increase in the prevalence of ACS $(P=0.002)$. Smoking, in turn, caused a 10.4-fold increase in the risk of ACS $(\mathrm{P}=0.001)$. Patients with ACS were evaluated by cardiac continuous monitoring for cardiac arrhythmias. Evaluations indicated cardiac arrhythmia in 10 patients including 4 cases of sinus tachycardia, 1 sinus bradycardia, 3 cases of frequent Premature Ventricular Complex (PVC), 1 case of Atrial Fibrillation (AF) and 1 case of sustained Ventricular Tachycardia (VT). Mean vitamin D level in the patient with arrhythmia was $18.42 \pm 9.11 \mathrm{ng} / \mathrm{mL}$. Mean levels of vitamin $\mathrm{D}$ in those lacking arrhythmia was $21.05 \pm 14.91 \mathrm{ng} /$ $\mathrm{mL}$, and the difference between vitamin $\mathrm{D}$ levels in the 2 groups was not significant $(\mathrm{P}=0.75)$. In addition, comparison between mean levels of vitamin $\mathrm{D}$ at different Ejection Fraction (EF) levels showed no significant difference ( $\mathrm{P}=$ $0.39)$.

\begin{tabular}{|lccc|}
\hline \multicolumn{4}{|l}{ Table1: Demographic Data, and Mean Levels of Lipid Profile, Vitamin D, Hypertension, and Diabetes in the Case and Control Groups } \\
Variable & Case & Control & P. value \\
Age $($ years $)$ & $63.26 \pm 10.76$ & $61.22 \pm 10.71$ & - \\
Vitamin D( $\mathbf{n g} / \mathbf{m l})$ & $20.63 \pm 13.90$ & $29.54 \pm 16.80$ & 0.002 \\
TG(mg/dL) & $166.52 \pm 121.6$ & $103.44 \pm 59.20$ & 0.002 \\
Chol(mg/dL) & $195.15 \pm 41.07$ & $164.60 \pm 38.26$ & 0.001 \\
HDL(mg/dL) & $41.06 \pm 9.43$ & $43.66 \pm 10.60$ & 0.21 \\
LDL $(\mathbf{m g} / \mathbf{d L})$ & $109.13 \pm 28.42$ & $92.02 \pm 29.67$ & 0.005 \\
Diabetes & $16(32 \%)$ & $5(10 \%)$ & 0.007 \\
Hypertension & $23(46 \%)$ & $9(18 \%)$ & 0.003 \\
Smoking & $35(70 \%)$ & $6(12 \%)$ & 0.02 \\
\hline
\end{tabular}

Chol, Cholesterol; HDL, High Density Lipoprotein; LDL, Low Density Lipoprotein; TG, Triglyceride 


\begin{tabular}{|lcccc|}
\hline \multicolumn{4}{|l}{ Table 2: Estimation of Adjusted Odds Ratio of Factors Influencing ACS With Adjustment for Other Confounding Factors $(\mathrm{CI}=95 \%)$} \\
Variables & Case $(\mathbf{n}=\mathbf{5 0})$ & Control(n= 50) & Adjusted OR & P. value \\
Age(years) & $63.26 \pm 10.76$ & $61.22 \pm 10.71$ & 1.05 & 0.084 \\
Vitamin D( $\mathbf{n g} / \mathbf{m l})$ & $20.63 \pm 13.90$ & $29.54 \pm 16.80$ & 0.939 & 0.005 \\
TG(mg/dL) & $166.52 \pm 28.3$ & $103.44 \pm 14.8$ & 1.002 & 0.62 \\
Chol(mg/dL) & $195.15 \pm 36.2$ & $164.60 \pm 23.9$ & 1.033 & 0.105 \\
LDL(mg/dL) & $109.13 \pm 19.7$ & $92.02 \pm 18.1$ & 0.98 & 0.380 \\
Smoking & $35(70 \%)$ & $6(12 \%)$ & 10.40 & 0.001 \\
Diabetes & $16(32 \%)$ & $5(10 \%)$ & 2.66 & 0.292 \\
Hypertension & $27(54 \%)$ & $9(18 \%)$ & 9.67 & 0.002 \\
\hline
\end{tabular}

Chol, Cholesterol; LDL, Low density lipoprotein; TG, Triglyceride; OR, Odds Ratio

\begin{tabular}{|c|c|c|c|}
\hline Variable & $\operatorname{Frequency}(\mathrm{n}=\mathbf{5 0})$ & Vitamin D $(\mathrm{ng} / \mathrm{ml})$ & P.value \\
\hline Arrhythmia & $10(20 \%)$ & $22.65 \pm 11.49$ & 0.75 \\
\hline \multicolumn{4}{|l|}{ Ejection Fraction* } \\
\hline Mild LVSD & $19(38 \%)$ & $18.64 \pm 13.28$ & \\
\hline Moderate LVSD & $22(44 \%)$ & $24.43 \pm 14.90$ & 0.39 \\
\hline Severe LVSD & $9(18 \%)$ & $18.42 \pm 9.11$ & \\
\hline
\end{tabular}

LVSD, Left Ventricular Systolic Dysfunction

*Normal LV Systolic Function: 60\% $\leq$ EF 65\% <, Mild LV Systolic Dysfunction: 60\% > EF $\geq 45 \%$, Moderate LV Systolic Dysfunction: 45\%

$>\mathrm{EF} \geq 30 \%$, Severe LV Systolic Dysfunction: EF < 30\%

\section{DISCUSSION}

This case-control study was conducted to compare vitamin D levels in patients with and without ACS. According to the results of this study, mean levels of vitamin $D$ were significantly lower in patients with ACS, and it was shown that for every one unit increase in vitamin D levels, the risk of ACS was reduced by $7 \%$. However, no significant correlation was found between serum levels of vitamin $\mathrm{D}$ and short-term complications of ACS, including cardiac arrhythmias and reduced left ventricular function. The mechanism by which vitamin $\mathrm{D}$ exerts a protective effect against cardiovascular disease is not clear yet. The proposed mechanisms include effects on renin-angiotensin system and the prevention of high blood pressure, control of blood sugar by increasing sensitivity to insulin, a direct effect on calcium metabolism in cardiovascular muscles, and an effect on the inflammatory system [16-18]. Similar to the current study, the majority of studies indicated the protective effect of vitamin D on cardiovascular disease, including ACS [14, 19-22]. In a number of studies, it was shown that a reduction in plasma levels of vitamin D was associated with the risk of ischemic heart disease, myocardial infarction, and sudden death [11,23-26]. However, in contrast to the current study, other studies did not indicate a significant relationship between serum vitamin D levels and the incidence of ACS, diabetes, hypertension, and smoking [27]. Other studies have even shown that the incidence of ACS is higher at higher levels of vitamin $D$, raising the need for further investigations to designate an optimum level of vitamin D for the prevention of cardiovascular diseases [28]. In accordance with the function of the left ventricle, the administration of vitamin $\mathrm{D}$ in people with vitamin $\mathrm{D}$ deficiency significantly increased the EF value in one study, [29, 30] which indicates a significant relationship between ventricular dysfunction and vitamin D levels. Vitamin D appears to influence cardiac function through the synthesis of contractor proteins in cardiac myocytes, as well as regulation of calcium metabolism [31, 32]. Although no link was found between serum vitamin $\mathrm{D}$ levels with cardiac arrhythmia in the current study, a number of studies have indicated vitamin $\mathrm{D}$ deficiency as an independent risk factor for arrhythmia [33-35].

\section{CONCLUSIONS}

This study suggests an independent link between serum vitamin D levels and acute coronary syndrome, after adjusting for confounding factors. However, no significant relationship was found between the levels of vitamin $\mathrm{D}$ and short-term cardiac effects (e.g. arrhythmia and reduced left ventricular function), following acute coronary syndrome.

\section{LIMITATIONS}

The most important limitation of this study was its small sam- 
ple size. In addition to the small number of patients, the study being conducted at a single should also be considered. Also, this study was designed to compare 2 groups of patients, ACS and non-cardiac diseases, thus the generalization of results should be done with caution.

\section{ACKNOWLEDGEMENTS}

The authors appreciate Mousavi Hospital, Zanjan as this study was not possible without their help.

\section{FUNDING}

This research received no grant from any funding agency in the public, commercial or not-for-profit sectors.

\section{DISCLOSURES}

The authors declare that there is no conflict of interest.

\section{AUTHOR CONTRIBUTIONS}

Design: Reza Hassanzadeh Makoui

Data collection: Mahsa Soltannejad Dizaji

Data analysis and interpretation: Reza Hassanzadeh Makoui Drafting the article: Hamid Khederlou Critical revision of the article: Reza Hassanzadeh Makoui Final writing and submitting: Hamid Khederlou

\section{REFERENCES}

1. Beyranvand M, Kolahi A, Ghafelebashi S. Charactristics and final diagnosis of patients with primary diagnosis of acute coronary syndrome. J Babol Univ Med Sci. 2008;10(3):76-82.

2. Kazemi SD, Jozanikohan Z, Assar O, Lotfian I. The effect of vitamin $\mathrm{D}$ deficiency on coronary artery stenosis severity in angioplasty patients in Baqiatallah hospital in 2013. Arak Med University J. 2014;16:70-5.

3. Thygesen K, Alpert JS, Jaffe AS, Simoons ML, Chaitman BR, White HD, et al. Third universal definition of myocardial infarction. J Am Coll Cardiol. 2012;60(16):1581-98. DOI: 10.1016/j. jacc.2012.08.001 PMID: 22958960

4. Longo D, Fauci A. Harrison`s Principle of Internal Medicine. 18th ed: McGraw Hill; 2015.

5. Milazzo V, De Metrio M, Cosentino N, Marenzi G, Tremoli E. Vitamin D and acute myocardial infarction. World J Cardiol. 2017;9(1):14-20. DOI: 10.4330/wjc.v9.i1.14 PMID: 28163832

6. Larijani B, Moradzadeh K, Keshtkar AA, Hossein-Nezhad A, Rajabian R, Nabipour I, et al. Normative Values of Vitamin D Among Iranian Population: A Population Based Study. Int J Osteop Metab Dis. 2008;1(1):8-15. DOI: 10.3923/ijom.2008.8.15

7. Sanchis-Gomar F, Perez-Quilis C, Leischik R, Lucia A. Epidemiology of coronary heart disease and acute coronary syndrome. Ann Transl Med. 2016;4(13):256. DOI: 10.21037/atm.2016.06.33 PMID: 27500157

8. Nadir MA, Szwejkowski BR, Witham MD. Vitamin D and cardiovascular prevention. Cardiovasc Ther. 2010;28(4):e5-12. DOI: 10.1111/j.1755-5922.2010.00192.x PMID: 20553279

9. Attia A, Emara A, Shoker A. Therapeutic Potential of 25-Hydroxyvitamin D in Promoting Cardiovascular Health. Arab Journal of Nephrology and Transplantation. 2010;3(2). DOI: 10.4314/ajnt. v3i2.58908

10. Stumpf WE, Sar M, Reid FA, Tanaka Y, DeLuca HF. Target cells for 1,25-dihydroxyvitamin D3 in intestinal tract, stomach, kidney, skin, pituitary, and parathyroid. Science. 1979;206(4423):1188-90. PMID: 505004

11. Pilz S, Marz W, Wellnitz B, Seelhorst U, Fahrleitner-Pammer A, Dimai HP, et al. Association of vitamin D deficiency with heart failure and sudden cardiac death in a large cross-sectional study of patients referred for coronary angiography. J Clin Endocrinol Me- tab. 2008;93(10):3927-35. DOI: 10.1210/jc.2008-0784 PMID: $\underline{18682515}$

12. Michos ED, Melamed ML. Vitamin D and cardiovascular disease risk. Curr Opin Clin Nutr Metab Care. 2008;11(1):7-12. DOI: 10.1097/MCO.0b013e3282f2f4dd PMID: 18090651

13. Bischoff-Ferrari HA, Giovannucci E, Willett WC, Dietrich T, Dawson-Hughes B. Estimation of optimal serum concentrations of 25-hydroxyvitamin D for multiple health outcomes. Am J Clin Nutr. 2006;84(1):18-28. DOI: 10.1093/ajcn/84.1.18

14. Kim DH, Sabour S, Sagar UN, Adams S, Whellan DJ. Prevalence of hypovitaminosis $\mathrm{D}$ in cardiovascular diseases (from the National Health and Nutrition Examination Survey 2001 to 2004). Am J Cardiol. 2008;102(11):1540-4. DOI: 10.1016/j.amjcard.2008.06.067 PMID: 19026311

15. Gasbarrini A, Serricchio M, Tondi P, Franceschi F, Ojetti V, Sanz Torre E, et al. Helicobacter pylori infection and vascular diseases. Ital J Gastroenterol Hepatol. 1998;30 Suppl 3:S307-9. PMID: 10077761

16. Wang TJ, Pencina MJ, Booth SL, Jacques PF, Ingelsson E, Lanier K, et al. Vitamin D deficiency and risk of cardiovascular disease. Circulation. 2008; $117(4)$ :503-11. DOI: $10.1161 /$ CIRCULATIONAHA.107.706127 PMID: 18180395

17. Zittermann A, Schleithoff SS, Koerfer R. Vitamin D and vascular calcification. Curr Opin Lipidol. 2007;18(1):41-6. DOI: $10.1097 /$ MOL.0b013e328011c6fc PMID: 17218831

18. Fitzpatrick LA, Bilezikian JP, Silverberg SJ. Parathyroid hormone and the cardiovascular system. Curr Osteoporos Rep. 2008;6(2):7783. PMID: 18778568

19. Yarjanli M, Hosseinpanah F, Azizi F. Association Between Vitamin D Deficiency and Cardiovascular Disease. Iranian J Endocrinol Metab. 2011;12(5):520-8.

20. Scragg R, Jackson R, Holdaway IM, Lim T, Beaglehole R. Myocardial infarction is inversely associated with plasma 25-hydroxyvitamin D3 levels: a community-based study. Int J Epidemiol. 1990;19(3):55963. PMID: 2262248

21. Giovannucci E, Liu Y, Hollis BW, Rimm EB. 25-hydroxyvitamin $\mathrm{D}$ and risk of myocardial infarction in men: a prospective study. Arch Intern Med. 2008;168(11):1174-80. DOI: 10.1001/ archinte.168.11.1174 PMID: 18541825

22. Douglas AS, Dunnigan MG, Allan TM, Rawles JM. Seasonal variation in coronary heart disease in Scotland. J Epidemiol Community Health. 1995;49(6):575-82. PMID: 8596091

23. Sun Q, Shi L, Rimm EB, Giovannucci EL, Hu FB, Manson JE, et al. Vitamin D intake and risk of cardiovascular disease in US men and women. Am J Clin Nutr. 2011;94(2):534-42. DOI: 10.3945/ ajcn.110.008763 PMID: 21653796

24. Brondum-Jacobsen P, Benn M, Jensen GB, Nordestgaard BG. 25-hydroxyvitamin $\mathrm{d}$ levels and risk of ischemic heart disease, myocardial infarction, and early death: population-based study and meta-analyses of 18 and 17 studies. Arterioscler Thromb Vasc Biol. 2012;32(11):2794-802. DOI: 10.1161/ATVBAHA.112.248039 PMID: 22936341

25. Dobnig H, Pilz S, Scharnagl H, Renner W, Seelhorst U, Wellnitz B, et al. Independent association of low serum 25-hydroxyvitamin $\mathrm{d}$ and 1,25-dihydroxyvitamin d levels with all-cause and cardiovascular mortality. Arch Intern Med. 2008;168(12):1340-9. DOI: 10.1001/ archinte.168.12.1340 PMID: 18574092

26. Lund B, Badskjaer J, Lund B, Soerensen OH. Vitamin D and ischaemic heart disease. Horm Metab Res. 1978;10(6):553-6. DOI: 10.1055/s-0028-1093390 PMID: 744575

27. Boshtam M, Rafiei M, Sarrafzadegan N, Mostafavi S, Naderi G. The relationship between serum vitamin $\mathrm{D}$ level, coronary artery disease and the associated risk factors in female carpet weavers. J Qazvin Univ Med Sci. 2005;35:44-52.

28. Rajasree S, Rajpal K, Kartha CC, Sarma PS, Kutty VR, Iyer CS, et al. Serum 25-hydroxyvitamin D3 levels are elevated in South Indian patients with ischemic heart disease. Eur J Epidemiol. 2001;17(6):56771. PMID: 11949730

29. Amin A, Minaee S, Chitsazan M, Naderi N, Taghavi S, Ardeshiri M. Can vitamin D supplementation improve the severity of congestive heart failure? Congest Heart Fail. 2013;19(4):E22-8. DOI: 10.1111/chf.12026 PMID: 23517460

30. Bae S, Singh SS, Yu H, Lee JY, Cho BR, Kang PM. Vitamin D signaling pathway plays an important role in the development of heart failure after myocardial infarction. J Appl Physiol (1985). 2013;114(8):979-87. DOI: 10.1152/japplphysiol.01506.2012 
PMID: 23429874

31. Cioffi G, Gatti D, Adami S. [Vitamin D deficiency, left ventricular dysfunction and heart failure]. G Ital Cardiol (Rome). 2010;11(9):64553. PMID: 21348179

32. O'Connell TD, Giacherio DA, Jarvis AK, Simpson RU. Inhibition of cardiac myocyte maturation by 1,25-dihydroxyvitamin D3. Endocrinology. 1995;136(2):482-8. DOI: $10.1210 /$ endo.136.2.7835280 PMID: 7835280

33. Walters MR, Ilenchuk TT, Claycomb WC. 1,25-Dihydroxyvita- min D3 stimulates 45Ca2+ uptake by cultured adult rat ventricular cardiac muscle cells. J Biol Chem. 1987;262(6):2536-41. PMID: $\underline{3818607}$

34. M T, Bailey B, Chowdhury F, Finton C, Manning T, Peiris A. Relationship of Vitamin D Status to Cardiac Arrhythmias in Veterans. Circulation. 2011;4:111-7.

35. Demir M, Uyan U, Melek M. The effects of vitamin D deficiency on atrial fibrillation. Clin Appl Thromb Hemost. 2014;20(1):98-103. DOI: $10.1177 / 1076029612453762$ PMID: 22826443 